\title{
A Parameterization of X-Ray Production in Laser-Produced Plasmas
}

James M. Peek

Prepared by Sandia National Laboratories, Albuquerque, New Mexico 87185 and Livermore. California 94550 for the United States Department of Eneray under Contract DE-ACO4-76DP00789

Printed October 1980

\section{Sandia National Laboratories}




\section{DISCLAIMER}

This report was prepared as an account of work sponsored by an agency of the United States Government. Neither the United States Government nor any agency Thereof, nor any of their employees, makes any warranty, express or implied, or assumes any legal liability or responsibility for the accuracy, completeness, or usefulness of any information, apparatus, product, or process disclosed, or represents that its use would not infringe privately owned rights. Reference herein to any specific commercial product, process, or service by trade name, trademark, manufacturer, or otherwise does not necessarily constitute or imply its endorsement, recommendation, or favoring by the United States Government or any agency thereof. The views and opinions of authors expressed herein do not necessarily state or reflect those of the United States Government or any agency thereof. 


\section{DISCLAIMER}

Portions of this document may be illegible in electronic image products. Images are produced from the best available original document. 
Issued by Sandia Laboratories; operated for the United States Department of Energy by Sandia Corporation.

\section{NOTICE}

This report was prepared as an account of work sponsored by the United States Government. Neither the United States nor the Department of Energy, nor any of their employees, nor any of their contractors, subcontractors, or their employees, makes any warranty, express or implied, or assumes any legal liability or responsibility for the accuracy, completeness or usefulness of any information, apparatus, product or process disclosed, or represents that its use would not infringe privately owned rights.

Printed in the United States of America

Available from

National Technical Information Service

U. S. Department of Commerce

5285 Port Royal Road

Springfield, VA 22161

Price: Printed Copy $\$ 4.00$ Microfiche $\$ 3.00$ 


\section{PAGES 1 to 2 WERE INTENTIONALLY LEFT BLANK}


A PARAMETERIZATION OF $X$-RAY PRODUCTION IN LASER-PRODUCED PLASMAS *

James M. Peek

Sandia National Laboratories

Albuque rque, New Mexico 87185

\begin{abstract}
A simple and algebraically tractable model is developed for the effic: ency of $x$-ray production in a certain spectral region by laser driven plasmas. The model is used as an interpolation/extrapolat lit device for experimental and theoretical results from three different target concepts. These tests indicate that it is of use in its Intended capacity. Certain relatlonships between Independent parameters aid scaling laws also result from this construction. Most notable among these is the prediction that the efficiency for producing IIne radiation in a certain narrow energy range scales like the inverse square of this energy.
\end{abstract}

*This work supported by the U.S. Department of Energy

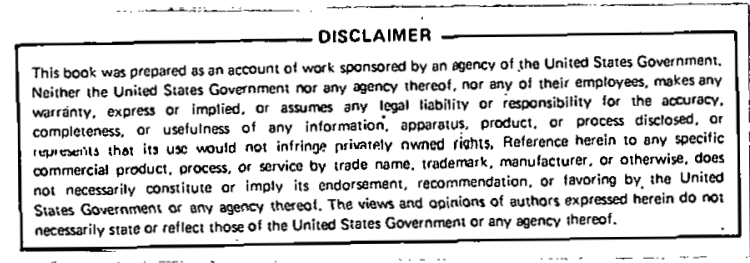




\section{Introduction}

Electromagnetic radiation from laser-driven plasmas has long been of interest. It is an important loss mechanism for laser-driven fuston experiments, ${ }^{1}$ but it has the potential to be a radiation source with characteristics that would be useful in many diverse applications. ${ }^{2} \mathrm{~A}$ number of experimental and theoretical studies of plectromagnetic radiatiun production, especially in the $x$-ray reglon, has been prompted by these considerations. The experimental measurements are romplicated by the difficulties of measuring absolute intensity under adverse conditions. The theoretical work usually consists of computer-hased studico using models that necessarily include large quantities of numerical data to describe the relevant atomic properties. Hence, a complete characterization of the large parameter space for such studles w11l not soon be avallable.

The purpose of this work 18 to construct a iudel capable of correlating avallable information on $x$-ray production by laser-driven plasmas while retalning a simple and relatively tranoparent depeadence on the relevant parameters. The property of central interest is the photon-production efficlency $\eta$ for photons with energy near or exceeding some value $\Delta E_{s}$. The emphasis is on simplicity. Obviously, there is no hope of incorporating ali of the 1mportant physics into an algebraically tractable form. The approach used here to achieve this goal is to isolate the more relevant parameters and then derive the desired relationships hy representing the many unattended complexities with empirical normalization constants. These constants will be determined by appeal to the avallable experimental and/or theoretical results. 
This model is reasonably successful in correlating certain theoretical data for three quite different targets. In addition, an analysis of some experimental data from the study of laser interactions with solid targets is presented. Two empirical constants are required to predict $\eta$. The relationship between the values found for these constants provides some physical insight in two of the applications and they quantify the relative ordering of $\eta$ for all three applications.

Such a model provides correlation/extrapolation information that should be useful in choosing parameters for future experiments or large-scale computations. However, because of the limited experience with this simple model, caution is obviously necessary in using it as an extrapolation or scaling device. Most notable of the scaling predictions is the increase of $\eta$ with the square of the laser frequency and with the time the plasma absorbing the laser energy can be prevented from converting this energy to hydrodynamic motion, $\Delta t_{p}$. Also, $\eta$ is observed to be proportional to $\Delta \mathrm{E}_{s}^{-2}$ for the case of line radiation. This rapld decrease in line-radiation efficiency with increasing $\Delta \mathrm{E}_{s}$ results in an estimate that bremstrahlung and recombination radiation are each comparable to, or exceed, the intensity of line radiation for $\Delta E_{s} \geq 20 \mathrm{keV}$, even under optimal condition for the line-radiation process. Some collaborative information for these predictions is cited.

The construction of the model is presented in Section II. A discussion of the model's physical content and any anticipated caveats are also presented in Section II. Applications to three different types of targets are presented in Section III and summary information is given in Section IV. 


\section{Theory}

The production of radiation from a laser-driven plasma is modeled here by assuming a plasma with a fairly high conductivity has already been formed. Th1s plasma will be a relatively efficient absorber of the laser energy unless the laser frequency exceeds the electron plasma frequency. This provides one of our basic relationships,

$$
n_{p}=n_{e} \text { with } \quad n_{a}=\frac{n_{e}}{z-q} \quad .
$$

The number per unit volume of electrons, $n_{e}$, is equated to the concentration of electrons, that is required to produce a plaoma frcquency equal lu to the laser frequency, ${ }^{3} n_{p}$,

$$
n_{p} / \mathrm{cm}^{-3}=1.11 \times 10^{21}(\lambda / \mu \mathrm{m})^{-2}
$$

where $\lambda$ is the lager wave length. The optimal concentration of target atoms, $n_{a}$, after imposing the condition for over-all charge neutrality upon the plasma 16 aloo given in Eqs. (1). Heite $\Sigma$ is the nucleatr charge and $q$ is the number of electrons expected to be left on the target under the conditions created by the laser. The cholce of $q$ will be discussed later. Equation (1) and the following developments are based on the assumption that the target material consists of a single $z$. Generalization to more complex targets is straightforward.

The mechanisms for the laser-11ght ahsorption will not be trcated in this simplified approach. Instead, an artificlal electron temperature $T_{e}$ 1s defined by relating it to the incident laser energy $J_{1}$ through

$$
(3 / 2) \mathrm{kT}_{\mathrm{e}}=\varepsilon_{\mathrm{d}} \mathrm{J}_{\mathrm{i}} /\left(\mathrm{Vn}_{\mathrm{e}}\right)
$$


where $V$ is the volune of the plasma heated by the laser and $\varepsilon_{d}$ is an efficlency of depositior parameter to be determined. The value of $\mathrm{T}_{e}$ reflects an average of the electron temperature over $V$ and the time the plasma can radiate, $\Delta t_{r}$. Typically, $\Delta t_{r}$ would be equated to the lesser of the plasma disassembly time or the time required for significant cooling of the plasma. Hence, a judiclous choice of $\mathrm{T}_{e}$ for a given $\mathrm{J}_{1}$ and experimental situation is required to determine $\varepsilon_{\mathrm{d}}$ :

Equation (2) requires the electron degrees of freedom to be thermally equilibrated on a time scale short compared to $\Delta t r$ This seems reasonable since the equilibrium time for electron degrees of freedom under conditions corresponding to a Nd-glass laser is short, less than $10^{-11}$ sec for $\mathrm{n}_{\mathrm{e}} \sim 10^{21} \mathrm{~cm}^{-3}$ and $\mathrm{kT} e \leq 10 \mathrm{keV}$ compared to the time scales for other processes such as plasma expansion. Very roughly, this time scales 1 ike $\left(\lambda / \lambda_{0}\right)^{2}$ for other lasers, where $\lambda_{0}$ is the Nd-glass laser wave length and $\lambda$ is the wave length for the laser in question. In addition, the time for a linear dimension of the plasma $d_{0}$ to double by free expansion is about

$$
\left.1_{o} \sqrt{m_{a} /\left(3 k T_{e}\right.}\right)=1.6 \times 10^{-8}\left(d_{o} / c m\right) \sqrt{\left(m_{a} / m_{e}\right)\left(k e V / k T_{e}\right)} \mathrm{sec}
$$

where $m_{a}$ is the target atomic mass and $m_{e}$ is the electron mass. Hence the electron thermalization time is expected to be short compared to the free-expansion time for typical conditions.

The classical absorption mechanism, 1.e., Inverse bremsstrahlung, would appear to well satisfy this view. Anomalous or collective absorption effects, which become increasingly Important for increasing laser peak-power or decreasIng laser pulse lengths $\Delta t_{\&}$, tend to produce a non-thermal high-energy electron distribution strongly decoupled from the thermalized electrons. ${ }^{4}$ It 1 s beyond the scope of this work to deal with this problem other than to point out that Eq. (2) may not be well suited to the anomalous absorption case. 
The next step in this simplified model consists of constructing an equation describing the efficlency of radiation production in the range of energy defined by $\Delta \mathrm{E}_{\mathrm{s}}$. Line radiation, radiative recombination, and bremsstrahlung can all contribute and results for each of these three forms of radiation are presented. Conditions that optimize line radiation $5-8$ are of central interest since 1 t 16 anticlpated that thcse conditions also optimize Llie lulal $\Delta E_{s}$ radlailun from the plasma. Hence these condielons ate discussed and the derivation of the line-radiation results are presented in some detall. The abbreviated treatments of recombination and bremsitrahlung follow.

The conditions that give rise to the large line radiation component correspond to a $\mathrm{kT}_{e}$ having the same order of magnitude as the excitation energy for a transition with a unit change in principle quantum number, $\Delta p=1$ from a shell with principle quantum $p_{0}$, where $p_{0}$ is the largest shell with signiflcant occupation. See, for example, Refs. 5 and 9 . Data in Table I of Ref.9 for steady-state corona condition indicate, for example, that $\mathrm{kT}, \sim 0.33 \Delta \mathrm{E}$ results in equal concentration of completely stripped and hydrogen-1ik.e nxygen aluius. Hele $\Delta z$ ls llie energy of a $\Delta p=1, p_{0} \equiv 1$ tràsition in hydrogenlike oxygen. This proportionality constaut between $k T$ and $\Delta \mathrm{E}_{s} 1$ ncreases as the nuclear charge increases and also one expects that $\mathrm{kT}_{\mathrm{e}}$ must be 1 ncreased to malntain this condition in a plasma that is too dense to satisfy the corona conditions. The time for lonfing all electrons in shells with $p>p_{0}$ will tend to be relatively short compared to the plasma life-t1me discussed above $^{3}$ while the life-time for stripping the $p_{0}$ shell can be significantly longer. ${ }^{3,10}$ The complexity of treating all of these considerations is considerable and will not be attempted. The gain in simplicity is balanced by the restriction of the theory's, applicability to relatively narrow range of $\mathrm{kT}_{\mathrm{e}}$. 
The rate of erergy production per unit of plasma volume by line radiation from all transitions to $p_{0}$ with $\Delta p \geq 1$ is approximated by the single term $n_{a} c\left(p_{0}, T_{e}\right) \Delta g_{s}$, where $c\left(p_{0}, T_{e}\right)$ is an electron excitation rate from the $p_{0}$ shell with $\Delta \mathrm{p}=1$. The quantity $\Delta \mathrm{E}_{\mathrm{S}}$ is equated to the corresponding excltation energy. The photon energy production $J_{0}$ in the energy range near $\Delta \mathrm{E}_{S}$ is then

$$
J_{0}=\varepsilon_{r}(b b) \quad \int_{t}^{t_{p}} d t n_{a} c\left(p_{0}, T_{e}\right) v \Delta E_{s}
$$

The temporal detalls of the plasma evolution will be lumped into the mean-value estimate

$$
J_{0} \simeq \varepsilon_{r}(b b) n_{a} \quad C\left(p_{0}, T_{e}\right) v \quad \Delta E_{s} \quad \Delta t_{p}
$$

Here $\varepsilon_{r}(b b)$ is a constant to be chosen for different applications and must in some way represent the large quantity of information neglected in this simple approach. The plasma radiation life-time is signified by $\Delta t_{p}$ of the many possible choices for the rate coefficient, a formula for the discrete excitation of positive lons

$$
\mathrm{c}\left(\mathrm{p}_{\mathrm{o}}, \mathrm{T}_{\mathrm{e}}\right)=9.87 \times 10^{-11} \mathrm{f} \alpha \mathrm{e}^{-1}(\mathrm{keV} / \mathrm{kT})^{-1.5}\left(\mathrm{ne}^{/ \mathrm{cm}^{-3}}\right) \mathrm{sec}^{-1}
$$

w111 be used. Equation (5) is an adaptation of one discussed elsewhere, $11 \mathrm{f}$ is the optical oscillator strength, and

$$
\alpha=\Delta E_{s} / k T_{e}
$$

Equations (1), (2) (4) and (5) can be used to construct the efficiency for line radiation, which is equated to $J_{0} / J_{1}$,

$\eta(\mathrm{bb})=6.58 \times 10^{-11} \varepsilon_{\mathrm{r}}(\mathrm{bb}) \varepsilon_{\mathrm{d}}\left(\frac{\mathrm{n}_{\mathrm{e}} / \mathrm{cm}^{-3}}{\mathrm{z}-\mathrm{q}}\right)\left(\Delta \mathrm{t}_{\mathrm{p}} / \mathrm{sec}\right)\left(\Delta \mathrm{E}_{\mathrm{s}} / \mathrm{kev}\right)^{-1.5} \mathrm{f} \alpha^{3 / 2} \mathrm{e}^{-\alpha}$ 
Equations (2) and (7) form the desired result and predict the efficiency for radiation production by lines in the $\Delta \mathrm{E}_{\mathrm{S}}$ range once $\varepsilon_{\mathrm{r}}$ and $\varepsilon_{\mathrm{d}}$ are assigned.

The efficlency for producing recombination or free-bound radiation with energy greater than or equal to $\Delta \mathrm{E}_{S}$ is computed by adapting the hydrogenic formula, see p. 195 of Ref. 12, to this problem. The relationship

$$
\Delta E_{s}=z_{e f f}^{2} \quad E_{H} / p_{o}^{2}
$$

is assumcd, where $Z_{\text {eff }}$ is an effective nuclear charge for the most populous Ion and $\mathrm{w}_{\mathrm{H}}$ is the hydrogen lonization energy. If one assumes that all ions of the plasma have this effective charge and that the lower $11 \mathrm{mit}$ on the radiation into all levels with $p \geq p_{0}$ is $\Delta E_{s}$, the efficlency for recombination radiation with energy equal to or greater than $\Delta \mathrm{E}_{S}$,

$\eta(\mathrm{fb})=7.43 \times 10^{-14} \varepsilon_{\mathrm{r}}(\mathrm{fb}) \varepsilon_{\mathrm{d}} \alpha^{3 / 2}\left(\Delta \mathrm{E}_{g} / \mathrm{keV}\right)^{1 / 2}\left(\frac{\mathrm{n}_{\mathrm{e}} / \mathrm{cm}-3}{\mathrm{z}-q}\right)\left(\Delta \mathrm{t}_{\mathrm{p}} / \mathrm{s}_{\mathrm{o}}\right)\left\{\mathrm{r}_{\mathrm{o}}+2 \mathrm{p}_{\mathrm{o}}{ }^{4}\left(2 \mathrm{p}_{\mathrm{o}}+1\right)^{-2}\right\}$

is easily established with the use of $E q$. (2). Here $\varepsilon_{\mathrm{r}}(\mathrm{fb})$ roplaceo $\mathrm{c}_{\mathrm{r}}(\mathrm{bb})$ appearing in Eq. (7) and the $\{\cdot \cdot \cdot\{$ term is a good approximation for all po to an infinite sum over $p$ that appears in the hydrogenic formula for power trom recomblination radiation. 12

The efficlency for producing radiation with energy greater than or equal to $\Delta \mathrm{E}_{\mathrm{s}}$ by bremsstrahlung is also easily computed if one assumes the hydrogenic formula for the bremsitrahlung emission coefficlent, see page 193 of Ref. 12, and follows the procedures used in deriving Eq. (7). The result is

$\eta(f f)=2.02 \times 10^{-15} \varepsilon_{r}(f f) \varepsilon_{d} \sqrt{\alpha} e^{-\alpha}\left(\Delta E_{s} / k e V\right)^{-1 / 2} z^{2}\left(\Delta t_{p} / s e c\right) \frac{n_{e^{/ c m}}{ }^{-3}}{z-q}(10)$ 
In this case an etfective nuclear charge or an equivalent to Eq. (8) was not introduced. The partial screening of the nucleus by any bound electrons wi11 reduce the effective value of $z^{2}$ in the numerator, hence Eq. (10) tends to provide an upper bound to $\eta$ (ff).

Equations (7), (9), and (10), when used with Eq. (2), allow a prediction of the efficiency for $\Delta E_{s}$ radiation once $\varepsilon_{d}$ and the $\varepsilon_{r}$ parameters are determined. However, the connection of Eq. (2) with the usual laser parameters needs some amplification. Two distinct cases occur. In the case of a preformed plasma the relationship

$$
n_{e} V=\text { constant }
$$

is presumed. In one example treated here, this plasma is assumed to be completely irradiated by the laser so the plasma is cylindrical in shape. The laser pulse is idealized as a guassian with unfform intensity over the spot size $A$. If the pulse width at one-half maximum power, $W_{0}$, is $\Delta t_{\ell}$ and the maximum power per unit area is $\phi_{0}$, then

$$
\mathrm{J}_{1}=0.60 \sqrt[1]{\pi} \Delta \mathrm{t}_{\ell} \mathrm{W}_{0}=0.601 \sqrt{\pi} \Delta \mathrm{t}_{\ell} \mathrm{A} \phi_{0}
$$

results. A different relationship may be required for other applications. The second case ts typical of laser interactions with large mass targets where the active volume of the plasma is not a constant. In these cases, the relationship

$$
n_{e} v=\zeta J_{1}^{1-m}
$$

replaces Eq. (11). Here $\zeta$ is not known and may depend very much on the detalls of the application. The quantity m also must be determined from data that are given. A number of theoretical and experimental studies of this 
paratneter are avallable. See, for example, Ref. 13 and the discusslons and citations in Ref. 14. This has the effect of introducing another empirical constant into the theory and rakes it impossible to independently determine a value for $\varepsilon_{\mathrm{d}}$. Relationships like Eq. (12) are st1ll applicable to this case but the laser and plasma parameters are no longer as clearly related as they were in the preformed-plasma application.

Some restrictions are implicit in this derivation. Also, after an assignment of the various parameters has been made for a particular set of conditions, the extrapolation of these predictions to a situation remote froin those used in the normalization may lead to serlous error. Items that make these statements necessary are: 1) The electron concentration must be near to but less than the plasma critical electron density. Equation (1) expresses only the optimal condition for the target concentration. 2) The time scales appear completely arbitrary, but restrictions such as $\Delta t_{\ell} \leq \Delta t_{p}$ seem obvious. Also, $\eta$ can be made greater than unity by arbitrarily increasing $\Delta t_{p}$. Certain natural limitations on $\Delta t_{p}$ will become evident in the applications. 3) No restrictions were placed on the cholce of $\mathrm{p}_{0}$. However, one expects various factors to change with different $p_{0}$. For example, $\Delta p=0$ transitions are not important for large $Z$ and $P_{0}=1$ (K-shell fluorescence or recombination for $\eta(b b)$ or $\eta(f b)$, respectively) but for $p_{0}>1$ they can be extremely important. 15 Also, the specification of the effective number of radiating electrons, or, equivalently the oscillator strength appearing in Eq. (3) becomes more arbitrary for increasing $\mathrm{p}_{0}$. 4) Equation (7) reflects the number of electrons contributing to line radiation through the cholce of $f$. Obviously, $f$ should be a function of $k r_{e}$. Here $f$ will be taken as a constant and the property that $f$ must vanish as the occupancy of the $p_{0}$ shell goes to zero, with increasing $\mathrm{kT}_{\mathrm{e}}$ replaced by the knowledge that Eq. (7) becomes an extrene upper bound for $\mathrm{KT}_{\mathrm{e}}>\Delta \mathrm{E}_{\mathrm{g}}$. 
The extension to $\mathrm{kT}_{\mathrm{e}}<\Delta \mathrm{E}_{\mathrm{s}}$ is more secure, but $\eta(\mathrm{bb})$ will again tend to be an upper hoind if weaker $\Delta p>1$ excitation rates replace the $\Delta p=1$ rate due to filling of the $p_{0}+1$ shell. Occupation arguments also make the cholce of $p_{0}$ in Eq. (9) a function of $\mathrm{kT}_{e}$. In this case, $\mathrm{p}_{0}$ is related to $\Delta \mathrm{e}_{\mathrm{s}}$ through $\mathrm{Eq}$. (8), or $\mathrm{Eq}$. (14) and (15) below, and obviously recombination radiation to the $p_{0}$ shell is suppressed due to the increased occupancy of the $p_{0}$ level for decreasing $k T_{e}$. Again, these considerations will be 1 gnored and the restricted usefulness of Eq. (9) accepted for $\mathrm{kT}_{\mathrm{e}} \ll \Delta \mathrm{E}_{\mathrm{s}}$. The ambigulty in occupation also effects the cholce of q for Eqs. (7), (9) and (10). Equation (1) can strictly reflect charge neutrality only if one ionic charge is found in the plasma. Since this is unlikely for most situations, the cholce for $q$ must represent some effective number of bound electrons and, as ts the case for $f$, it will not display the actual complex dependence on $k \mathrm{~T}_{e}$, $\mathrm{n}_{e}$, etc. As indlcated in the discussion following $\mathrm{F}_{\mathrm{q}} \cdot(10)$, the use of $\mathrm{Z}^{2}$ will tend to make this formula an upper bound. This restriction Is somewhat less critically related to the occupancy, so the predictions of $\eta$ (ff) should be more uniform over a larger range of $\mathrm{kT}_{e}$. 5) The effect of collislonal relaxation of excited states is only included in $\eta(b b)$ through the parameter $\varepsilon_{r}(b b)$. Collisional relaxation rates are proportional to $n_{e}$ and spontaneous radiation rates are proportional to $\Delta \mathrm{E}_{S}{ }^{3}$ for the line-radiation case. Hence, extrapolating $\mathrm{Eq} .(7)$ as determined for one set of conditions to larger ne or smaller $\Delta E_{s}$ will result in underestimating the collisional relaxation and overestimating $\eta(\mathrm{b} b)$. Similar arguments apply to $\eta(\mathrm{fb})$. A more detailed analysis of this problem can be constructed from the information provided by Ref. 9 . 6) The line and recombination radiation are characterized by a single value for $\Delta E_{s}$. The actual range of transition energies implied by $\Delta E_{s}$ increases, on a relative basis, as $p_{0}$ increases. Hence, the application of Eqs. (7) and (9) become more-questionable as one proceeds from considering $\mathrm{K}$-shell to L-shell 
to -shell etc. radiation. Further, convenient relationships between $\Delta \varepsilon_{s}$, $z$, and $p_{0}$ are desired. Since high accuracy is not required, the hydrogenic re.iat tonsh1p

$$
\Delta E_{s}=27.21\left[\frac{(z-s)^{2}}{2 p_{0}^{2}}-\frac{\left(z-s^{\prime}\right)^{2}}{2\left(p_{o}+1\right)^{2}}\right] \quad \mathrm{eV}
$$

Is useful, where $s, s^{\prime}$ are screening parameters appropriate to the $\Gamma_{u} \Gamma_{u}+1$ levels.16 Equation (14) w1ll in fact only be used for the $p_{0}=1$ or $\mathrm{K}$-shell case. A inoce accurate procedure is to rewrite Eq. (14) in the form

$$
\Delta E_{s}=I\left(p_{0}, z, q\right)\left\{1-\left[\frac{p_{0}\left(z-q^{\prime}\right)}{\left(p_{0}+1\right)(z-s)}\right]^{\varepsilon}\right\}
$$

where $I\left(p_{0}, z, q\right)$ is an ionization energy for an Ion described by the lndicated parameters. Ionfzation-energy data for all atoms and ions are avallable in conventent form. 17 Equations (14) and (15) are written for the line radiation case. The appropriate form for recomblnation radiation is obtained by dropplng the second terms in Eqs. (14) and (15). Bremstrahlung does not require a comparable relationship. For conventence, values based on Eq. (14) for K-shell line radiation and Eq. (15) for $L$ - and $M-$ shell line radlation are presented in Table I. Ground-state configurations for 2-, 7-, and 19-electrnn Inns were assumed for $K, L$ - and $M$-shell radiation In constructing Table $I$. Different cholces for these various shells give a measure of the increasing problems in going to radtation from higher shell that were mentloned in the preceding tiscussion.

A number of Interesting predictions are Indlcated by Eqs. (7), (9), and (10). First, the efficlency for all three is proportional to $\Delta t_{p}$ and $n_{e}$. Experimental control of $\Delta t_{p}$ nay be difficult, but $n_{e}$ is proportional-to the 
square of the lase: frequency, see the discussion following Eq. (1), and can be varied over a rathẹr wide range. There are considerable experimental data for laser-solid target interactions and evidence supporting this prediction is outlined in the following section.

The temperature dependence of the efficlency for the three types of radiation is not the same. The optimum efficlency for line radiation occurs at

$$
\alpha=1.5 \text { or } \Delta E_{s}=1.5 \mathrm{kT}_{\mathrm{e}}
$$

and at

$$
\alpha=0.5 \text { or } \Delta E_{s}=0.5 \mathrm{kT} e
$$

for bremsstrahlung. The formula for recombination radiation, Eq. (9), shows no optimum as a function of $\alpha$ or $\mathrm{kT}_{\mathrm{e}}$. This behavior 1s, none the less, qual1tatively correct. For example, if a condition like $\mathrm{kT}_{\mathrm{e}} \sim \Delta \mathrm{E}_{\mathrm{s}}$ is achieved to satisfy the occupation requirements of Item 4), and subsequently $\mathrm{kT}_{\mathrm{e}}$ is somehow rapidly lowered, the recombination efficiency predicted by $\mathrm{Eq} \cdot(9)$ increases like $\left(\mathrm{kr}_{\mathrm{e}}\right)^{-1.5}$. Th1s mechanism has been proposed as a method for building an $x$-ray laser. 18

The relative efficiency of the various types of radiation is of some interest. The ratio of bremstrahlung to line radiation turns out to be

$$
R_{f f}=3.07 \times 10^{-5} z^{2}\left(\Delta E_{s} / k e V\right)(\alpha f)^{-1}\left[\varepsilon_{r}(f f) / \varepsilon_{r}(b b)\right]
$$

and the analogous ratio for recombination radiation is

$$
R_{f b}=1.13 \times 10^{-3}\left(\Delta E_{s} / k e V\right)^{2} f^{-1} e^{\alpha}\left[\varepsilon_{r}(f b) / \varepsilon_{r}(b b)\right]\left\{p_{o}+2 p_{o}^{4}\left(2 p_{o}+1\right)^{-2}\right\}
$$


If one ignores the presence of the $\varepsilon_{r}$ rat10, takes $f=2, P_{0}=1$ (K-shel1 radiation) and assumes the optimum condition for line radiation, Eq. (16), . it is easily demonstrated that $R_{f f} \geqslant 0.3$ for $\Delta E_{s} \geqslant 20 \mathrm{keV}, 2 \geq 45$ and that $\mathrm{R}_{\mathrm{fb}} \geqslant 1$ for $\Delta \mathrm{E}_{\mathrm{s}} \geq 18 \mathrm{keV}$. (See Table T.) Th1s relative weakening of $\eta(\mathrm{bb}$ ) for $\Delta E_{s}>20 \mathrm{keV}$ is caused by its proportionality to

$$
(7-q)^{-1}\left(\Delta F_{s}\right)^{-1.5} \sim \Delta E_{s} s^{-2}
$$

which follows from Eqs. (7) and (14). This scaling is qualitatively 11ke the results of more elaborate calculations 8,10 and expcriment, ${ }^{19}$. where high frequency radiation appears to be suppressed relative to expectations. Finally, the optlcal osclilator strength $f$ is qualitatively like the number of electrons in the $p_{0}$ shell. See Items 4) and 6) presented in the prevtous discussion. Hence, the choices of $\mathrm{f}$ appearing in Eq. (7) for $\mathrm{K}$-shell, L-she11, etc. fluorescence should be proportional to $2 \mathrm{p}_{0}{ }^{2}$ where $\mathrm{p}_{\mathrm{o}}=1,2, \ldots$ for $\mathrm{K}-, \mathrm{L}-, \ldots$ she1ls. On the other hand, If one desires a common $\Delta \mathrm{E}_{\mathrm{s}}$ from these processes with differing $\mathrm{p}_{0}$, Table I indicates that Z-q must also increase. If the number of electrons bound to the target, $q$, is defined as number of electrons in shells with $p<p_{0}$ and $k T$ is assumed to be flxed, the over-all effect predicted by Eq. (7) is that the L-shell Is about twice the K-shell and about equal to the M-shell fluorescence. The recombination radiation is predicted by Eq. (9) to have the ratios 1: $0.8: 0.15$ for $\mathrm{K}-, \mathrm{L}-$, and $\mathrm{M}-$ shell processes $1 \mathrm{f}$ one assumes the same conditions. Bremsstrahlung ts proportional to $Z$, so for these conditions 1t becomes mote Important as one goes from $\mathrm{K}$ - to $\mathrm{L}$ - to $\mathrm{M}$ - shell mechanisms. This bremsstrahlung estimate may emphasize large 2 too much as was discussed In Item 4). The above arguments indicate that for radiation with $\Delta r_{\mathrm{s}}<.20 \mathrm{k} \mathrm{V}$, the best efficiency can be achieved by optimizing the experimental parameters 
for L- or M-shel1 line radiation. Mechanisms 1nvolving the L-shell are probably preferred because of points raised in Items 3) and 6). Expertmental and theoretical data $14,20,21$ that in part justify these predictions are discussed in Sec. III.

\section{Applications}

Theoretical data from three different plasma configurations will be studied within the framework just presented. A considerable quantity of experimental data are available for laser interactions with solid surfaces, so only a sample set of these data, chosen to best test the results presented In Sec. II, will be discussed. Again, the object of the applications is to test the Interpolation or extrapolation accuracy of the theory once the normalization constants have been assigned.

Uniform Preformed Plasmas: The plasma is assumed to be preformed by exploding wires ${ }^{5}$ or any other means. 10 The plasma is uniform in density with a cross section equal to the laser spot size $A$ and with a sufficlent length to absorb all of the laser energy. The plasma may be confined by external means; see Ref. 22 and the citations contained therein.

The detailed computation presented in Ref. 5 conforms almost exactly to the stated requirements. They treat aluminum targets preformed by exploding wires. Equation (14) indicates that $\Delta E_{S}=1.69 \mathrm{keV}$ for $\left(p_{0}=1, \Delta p=1\right)$ radiation. This corresponds falrly well to the energies expected from $H-$ and He-like $\Delta p=1$ transitions in aluminum. 5 other lines leading to $\mathrm{k}$-shell radiation, $\left(\mathrm{p}_{0}=1\right.$, $\Delta p>1)$, contribute as do lines leading to lower photon energies, $\left(p_{0}>1, \Delta p \geq 0\right)$. Under conditions ${ }^{5}$ optimal for total radiation production, the line radiation is also optimized and the ratio of brems/recombination/line radiation is 1/5/31. Equations (18) and (19) predict this proportionality to be $1 / 3 / 100$ 
for $\Delta E_{s}=1.69 \mathrm{keV}$ radiation. (The $\varepsilon_{r}$ terms were 1gnored.) In keeping with the motivation to preserve simpliclty, the rather clear dominance of line radiation suggests that the use of Eq. (7) alone to paranetertze the X-radiation dita of Ref. $S$ is a good approximation. The total radiation efficiency $\eta$, Is therefore equated to $\eta(b b)$ in the following developments.

Parameter values approprlate to the data presented In Ref. 5 are given in the Case 1 column of Tabile II. Most of the values Ilsted are țaken directly from Ref. 5. Exceptions include $q$ and $f$. The optlcal osclilator strength will coutinely be equated to the number of bound electrons in the active shell, $2 p_{0}^{2}$, and any adjustments required to this upper bound are assumed to be intorporated tnto $\varepsilon_{r}(b b)$. Cholces fot $q$ are based on the number of electruns in shells below the radiatively active shell. That is $q=0$ for the $\mathrm{K}-\mathrm{she} 11$ radiation, $q=2$ for the $L$-shell radiation, etc. The other extreme cholce would be to add to this $q$ the active $2 p_{0}^{2}$ electrons. This ambigulty in satisfylng the charge neutrality requirements of $\mathrm{Eq}$. (I) is another aspect of the difficulties discussed in Items 4) and 6) given in Sec. IL. The importance of this choice is minimized by the emplrical normalization but to will have some effect on the resulting extrapolation propertes.

Predictions based on these parameters are shown in Fig. 1, where $J_{0}$ is plotted versus $J_{1}$, as the solid curves. The straight line with undt slope represents the optimum efficiency, $\eta=0.23$, that can be expected. That Is, Eq. (16) Is assumed to be satisfled and the subsequent adjustment in V or A required by Eqs. (2) and (12) is Implied once $J_{1}$ has heen assigned. The remalning two curves in Fig. I represent the variation of the efficlency with $J_{1}$ for the two flxed spot slzes treated in Ref. 5. See the values for the radius of the laser spot size glven in Table İ for Case 1. The effect of $\varepsilon_{r}(b b)$ is to translate the solid curves in FIg. 1 vertically and the 
effect of $\varepsilon_{d}$ is $t_{i}$ ) change the values of $\left(J_{0}, J_{i}\right)$ for which the straight IIne becomes tangant to the curve. The shape of the curves is unchanged by the cholces of $\varepsilon_{d}$ or $\varepsilon_{r}(b b)$. This flexibility is severely tested by the broad range of parameters considered in Ref. 5. Indeed, the suggestion and Interpretation of the plot shown by Fig. 1 is about all that one might expect. The quantitative agreement is not particularly good; especially for conditions far removed from the optimal, but it is acceptable for such a simple model. See the closing discussion in Sec. II for reasons that suggest the failure of this model for conditions remote from those that give rise to maximal line radiation. Additional tests with data of the type provided by Ref. 5 would be useful and interesting.

The quantitative data provided in Ref. 10 are not presented in a form that is easily translated into the context of the present model, but their. summary observation that $\eta$ decreases strongly with increasing hardness of the radiation is consistent with the results given here. The present model can be applied to the type of plasma being studied in Ref. 22, but their cholce of parameters is more appropriate to radiation from the valence shell than to the present interest in inner-shell phenomena.

As a final step in presenting data for a homogeneous preformed plasma, the extrapolation of this theory to other targets, or general $Z$, and to $L-$ and M-shell radiation is presented. The parameters chosen for this exercise are given in Table II. Data are presented under the assumption that optimal conditions, as discussed above, have been achieved. The efficiency for K-shell line radiation is given in $\mathrm{Fig} .2$ as a function of both $\Delta \mathrm{E}_{\mathrm{s}}$ and $\mathrm{Z}$. The relationship between $\Delta E_{s}$ and $Z$ is given by Eq. (14). Also, see Table I. Analogous results for $L-$ and $M-s h e l l$ radiation are shown respectively in Figs. 3 and 4 . Equation (14) was replaced by Eq. (15) in the L- and M-shell calculations. 
Thesis figures graphically demonstrate the rapld decrease in efticiency with increasing $\Delta E_{s}$ and the limits placed on $\Delta E_{s}$ through the llatts imposed by $Z$. The curves presented In Figs. (2) - (4) are accurately represented by $\eta=c\left(\Delta E_{s} / k e V\right)^{-2}$. The observed values of $C$ are 0.67 for $K-$ shell radiation, 1.18 for L-shell radtation, and 1.28 for M-shell radlation. Hence lf everything else were equal, the efficlency for producing $\Delta E_{s}$ radtation increases with Increaslng $f_{n}$. Note should be taken ot the uncertainty in such a läge extrapolation from the conditions where tests agalnst. more rellable models were posstble and the discussion presented in Sec. II.

Hot-Spot Model: Keference 8 presents theoretical data for radiation from a sphere of uniform, stationary plasma with a radius $r$ equal to the radlus of the laser spot slze. Thls plasma is surrounded by a colder plasma to which the hot plasma loses energy by conduction. This is called the hot-spot nodel by its authors. Considerable detall is incorporated into this treatment and one of the major results presented is the $K-s$ hell fluorescence effictency as a function of $\mathrm{J}_{1}$. Hence it is again appropriate to equate the efficiency for producting $\Delta E_{s}$ radiation to $\eta(b b)$. Reference 8 considers carbon, fluorine, and aluminum targets.

The adaptation of the above theory to the hot-spot model is a stralghtforward task and the resulting parameters are listed under Case 5 In Table II. The only real amblgulty arises in trying to incorporate the conduction effects that are included in the hot-spot model. Not recognizing that the conduction effects will reduce $k T_{e}$ can be cxpected to be increasingly in error as $Z$ increases. This is simply due to the increase in electron conductivity with Increasing temperature. A model incorporating conductivity losses into $\varepsilon_{d}$ could be constructed, bist this seems beyond the spirit of the present approach. 
The first solution to the problem in choosing the two free parameters is to use the value found in the previous application for $\varepsilon_{d}$ and to adjust $\varepsilon_{r}$ (bb) to roughly reproduce the maximum magnitude of $\eta$ for the carbon case. This is equivalent to ignoring the conduction losses. The resulting predictions are shown as the broken curves in Fig. 5. The solid curves reproduce the data given by Ref. 8. The agreement is reasonable for carbon and fluorine but the aluminum prediction is considerably in error. The argument given in the above paragraph implies an adjustment of $\varepsilon_{d}$ should correct this situation and the value $\varepsilon_{\mathrm{d}}=0.4$ works quite well; see the dot-dash curve in Fig. 5 .

The present theory could be made to fit the Ref. 8 data quite accurately by treating $\varepsilon_{\mathrm{d}}$ and $\varepsilon_{\mathrm{r}}(\mathrm{bb})$ as arbitrary constants. Used as such, it provides a reasonably secure interpolation device. The rather reasonable agreement with intultive cholces for these parameters indicates that extrapolation of the hotspot model to other targets would provide bounds on the expected efficiency, and with a reasonable model for the conductivity losses incorporated into $\varepsilon_{\mathrm{d}}$, might provide at least semiquantitative extrapolation data.

Solid Surface Model: The interaction of a laser with a solid surface is quite complex and a complete theoretical treatment is not yet avallable. 19 One reason for the qualified success of theory is the existence of a large body of experimental data. No attempt will be made to provide a comprehensive review of this physics. Again, quantitative predictions are not possible but certain interpolation/extrapolation features appear useful and some interpretive insight 1s provided for the examples that are considered.

It is not possible to determine $\varepsilon_{\mathrm{d}}$ when Eq. (13) is applicable since

$$
\mathrm{kT}_{\mathrm{e}}=\varepsilon_{\mathrm{d}_{\mathrm{i}}}^{\mathrm{m}} / \zeta=\mathrm{c}_{1} \mathrm{~J}_{1}^{\mathrm{m}}
$$


is the operative relationship between $\mathrm{kT}$ and $\mathrm{J}_{1}$. Ohviously, only the ratio $c_{1}=\varepsilon_{d} / \zeta$ and $m$ can be determined if one is given values of $k T_{e}$ for a range of $J_{1}$ or, equivalently, $\phi_{0} \cdot$ The quantities $c_{1}$ and $m$ may be quite dependent on parameters defining the characteristics of the laser. At the same time the experimental observation that $\mathrm{kT}_{\mathrm{e}}$ is independent or very weakly dependent upon the target material for a given set of laser parameters suppurts the use ن Eys. (2), (11) - (13), and (20).14,21,23

The impossibility of determining $\varepsilon_{d}$ leads to rewriting Eq. (7) In the form

$$
\eta(b b)=c_{2} \alpha^{1.5} \theta^{\alpha}(\mathrm{z}-\mathrm{q})^{1}\left(\Delta \mathrm{E}_{\mathrm{s}} / \mathrm{kcV}\right)^{-1.5}
$$

where

$$
C_{2}=6.58 \times 10^{-11} \text { f } \varepsilon_{r}(b b) \varepsilon_{d}\left(n_{e} / \mathrm{cm}^{-3}\right)\left(\Delta t_{p} / \mathrm{sec}\right)
$$

Equations (21) and (22) have the mer1t of lumping together the parameters with greatest uncertainty and consequently expedites the following discusston. The following discussion concentrates on the production of line radiation so the obvious analogues for Eqs. (9) and (10) w111 not be presented.

Note that values of $\mathrm{C}_{2}$ can be deduced for the previous applications. These values are given in Table III.

The experimental data from Ref. 21 are reproduced in Fig. 6. They represent the measurement of radiation production from a series of solld materials with nuclear charge $Z$ for a fixed set of laser parameters. The value $k T_{e}=70 \mathrm{eV}$ applies to all of these data. The three different curves result from detectors sensitive to different ranges of $\Delta E_{s}$; see the figure caption. The three dashed curves are from Eq. (21), for K-, L-, and M- shell radiation reading from left to right. Normalization values, $C_{2}$ of Eq. (22), are given 
in Table III. Th? vertical dotted curves represent the $\mathrm{Z}$-dependence of the detectors.efficiency for $\Delta \mathrm{E}_{\mathrm{s}}$ radiation from the three shells. That is, a target to the left of the vertical line produces $\Delta \mathrm{E}_{\mathrm{s}}$ radiation at an energy too low to be detected while a target to the right will produce detectable radiation at the relative intensity indicated by the dashed curves. The peaks formed by the intersection of the dotted and dashed curves is an obvious ideallzation of the shape of the peaks due to line radiation. The essential features of Eq. (21) are the $Z_{1}$-values at which the peaks occur, this dependence on $Z$ as the detector energy response is changed, and the relative magnitudes of the peak heights. An increase in the peak widths as one goes from K- to L- to M- shell radiation is also predicted. Figure 6 indicates these properties are correlated best for the $\mathrm{K}$-shell case and the agreement is generally acceptable.

A number of inferences due to this theory can be made. For example, if thls experiment were repeated with a larger $k T_{e}$ the solid curves would be expected to move closer together, and vice versa. That is, the dashed lines become less steep with increasing $\mathrm{kT}_{\mathrm{e}}$. The positions of the peaks with respect to $Z$ will not change as $k T$ e changes since the locations of the dotted lines depend only on the energy range of the detectors. The ratio of peak height to the adjacent minfmum value should decrease as the detector response is IImfted to larger energy ranges. This is due to the strong decrease in Iine radiation with increasing $\Delta E_{S}$, relative to recombination and brems radiation, that was discussed in Sec. II.

Experiments simflar to the one described in connection with Fig. 6 have reported the efficiency of radiation production for differing lasers and/or laser parameters. $20,23,24$. These data will be fit to Eq. (21) with the object of testing Eq. (22) for consistency In going from K- to L- to M-shell 
radiation within a given experiment and for its ability to correlate the $\mathrm{C}_{2}$ values found for different experiments. The results of fitting Eq. (21) to these data are summarized in Table III. The values deduced for $\mathrm{C}_{2}$ from the earlier applications are also given. If one assumes that the only change in $\mathrm{C}_{2}$ for going to $\mathrm{K}$ - to $\mathrm{L}$ - to $\mathrm{M}$-shell radiation in a particular experiment is in the values for $f$, then the ratlos of $C_{2}$ are predicted to be $1: 4: 9$ for $K-$ to L- to M-she11 radiation. The experimental ratios are $1: 3.5: 6.3$ for Ref, 24, $1: 4.9: 3.8$ for Ref. 23, $1: 3.4: 1.4$ for Ref. 21 , and $1: 0.3$ for Ref. 20. The K- to L-shell experimental ratios are in acceptable agreement with the prediction but the M-shell experimental ratios are 1.4 to 6.4 times smaller than the prediction. The disparity in the M-shell ratios is nnt unlike that found in a more detalled corona-model calculation. 20 Considering the qualitative character of the theory, uncertainties in the experimental maxtma locations, and the great range of experfmental parameters, this is reasonably close to the ideal result of having onc value for $C_{2}$ Lhat scales according to Eq. (22) in going from K- to L- to M-shell processes for a glven experiment. Comparison of the $C_{2}$ values for $K-$ ohell radiation frum the various experiments shows that the preformed plasma of Ref. 5 is clearly the most efficlent radiator. This conforms to intultive expectations. According to Eqs. (1) and (22), and the scaling with laser frequency discussed in Sec. II, the Ref. 23 and 24 values for $C_{2}$ should be similar. They also should be $10^{2}$ times larger than the Ref. 20 values and 0.43 times smaller than the Ref. 21 values. The observed values are $10^{3}$ for the first case and the Ref. 21 valites are smaller than the Refs. 23 and 24 values. It should be noted that the Ref. 21 experiment was performed for $k T_{e} \ll \Delta E_{s}$, see Table III, and that the discusston presented in Sec. II anticipates difficultieg with this theory for conditions remote from those stated by Eq. (16). Th1s could explain the fallure of the 
Eq. (22) scaling between the Ref. 21 values and the Refs. 23 and 24 values. However, the available experimental evidence does not clearly support the scaling laws indicated by $\mathrm{Eq}$. (22) and further tests would be useful.

An Implication of Eqs. (13) and (20) should be noted. The restriction $0 \leq m \leq 1$ seems plausible with $m=1$ corresponding to the most efficlent result. See the above discussion. The infinite-mass targets 13,14 seem to produce $m \leq 0.35$. This could, in principle, be 1 mproved by going to a finitemass target thereby replacing Eq. (13) with Eq. (11). The avallable information on finite-sized targets 25 is not too promising but additional studies with this problem in mind would be interesting. Another indirect method that accomplishes the same end is to prepulse the target and create a finite quantity of plasma that then becomes decoupled from the remaining target mass. This preformed free plasma is then the target for the main laser pulse. Th1s design has been. studied with encouraging results. 24

The final application of Eqs. (20) - (22) w111 be to a theoretical computation of laser-solid interaction. 26 one purpose is to show how this parameter1zation can serve as an interpolation/extrapolation tool for large-scale computer calculations that treat the hydrodynamic and radiation complexities in somie deta11.26

The computation is for $1.06 \mu \mathrm{m}$ radiation on a flat $\mathrm{Ni}$ surface. The values m $=0.3$ and $C_{1}=0.11$ were determined by a rough fit of $\mathrm{Eq} \cdot(20)$ to the data shown in Fig. 7. The independent vartable $J_{1}$ could obviously be replaced by another such as $W_{0}$ or $\omega_{0}$ of Eq. (12). The relationship between these variables is of no interest for this application. The code value for the Ni L-shell fluorescence energy was $0.9 \mathrm{keV}$ and the recombination edge occurred at about $1.1 \mathrm{keV}$; values rather different from those expected and from those predicted by $\mathrm{Eq} \cdot(15)$. The value $\Delta \mathrm{E}_{\mathrm{s}}=1.0 \mathrm{keV}$ was used in this application. 
The value $\mathrm{C}_{2}=2.73$ was found by normalizing Eq. (21) to the code predictions for $J_{i}=800$ joules. The two sets of data taken from the code are shown in Fig. 8 and are described in this flgure's caption. The $\odot$ data that just span the $\mathrm{L}$-shell fluorescence and recombination radiation are both more appropriate to and better described by Eq. (21).

This parameterization indicates that the efficlency for $\Delta F_{6}$ radiation has peaked at 0.04 for $J_{1}=500$ joules. Further numeriral data may indieatc revi: sions are necessary, but the avallable data are reasonably well represented. Extrapolation to other targets or situations can be made by utilizing the scaling indicated by Eq. (22). Limftations on this procedure are indicated by the applications given above. The $m, c_{1}$ coefficlents of Eq. (20) must be considered unknown functions of the laser spot size, $\Delta t_{\ell}$, etc. but further numerical tests of the relationship provided here would be of much interest.

\section{Conclusions}

The relatively crude but algebraically tractable model proposed here proved successful as an interpolation/extrapolation device in a number of contexts. The major value of the model is to give guldance in planning further experiments or large-scale numerical investigations. ThLs model's predictions for improving the efficlency of and limitations on the production of radiation by laser driven plasmas, were discussed in detall. Some anticipated qualifications based upon the limited physlcal content of the model were also presented.

One of the most interesting predictions is the proportionability of the Iine-radiation efficiency to $\Delta \mathrm{E}_{\mathrm{s}}{ }^{-2}$. If this prediction is even qualitatively correct, it seems very unlikely for a laser-driven low-density plasma to be a competitive source to other schemes, such as traditional $x$-ray tubes or 
bremsstrahlung. converters, for $\Delta E_{s}>20 \mathrm{keV}$. Certain properties of the $Z$ and $\Delta E_{s}$ dependence of the radiation efficlency observed in a number of experimental studies were successfully correlated. Evidence was reviewed for the proportionality of the radiation efficlency to number of electrons in the radiatively active shell and to the square of the laser frequency. Some support was noted, but additional tests would be useful.

Acknowledgements

The author wishes to thank J.H. Renken for bringing the problem to his attention and helping to define the nature of the approach. Many colleagues have been very generous with their time and knowledge in contributing to this study. Kefth Matzen and John Anthes deserve speclal recognttion. 
References

1. K. A. Brueckner and S. Jorna, Rev. Mod. Phys. 46, 325 (1974).

2. D. J. Nage1, Adv. X-Ray Ana1. 18, 1 (1975); P.J. Ma1lozzi, H. M. Epstein, and R. E. Schwerze1, Adv. X-Ray Ana 1. 22, 267 (1979).

3. M. J. Bernstein and G. G. Comfsar, J. Appl. Phys. 4l, 729 (1970).

4. P. H-Y. Lee and M. D. Rosen, Phys. Rev. Letts., 42, 236 (1979).

5. D. Duston and J. J. Duderstadt, Phys. Rev. A 18, 1707 (1978); J. Appl. Phys. 49, $4388(1978)$.

6. D. G. Colombant, K. G. Whitney, D. A. Tidman, N. K. Winsor, and J. Davis, Phys. Fluids 18,1687 (1976).

7. W. H. Grasberger, C. E. Violet, and L. M. Richards, Bull. Am. Phys. Soc. 20, $682(1975)$

8. K. G. Whitney and J. Davis, J. Appl. Phys. 45, 5294 (1974), Appl. Phys. Lélls. 24, 509 (1974).

9. R. W. P. McWhirter, "Plasma Diagnostic Techniques" edited by R. H. Huddlestone aud 3. L. Leulard (Academile Press, New York, 1965) p. 2üi.

10. R. A. Shatas, T. G. Roberts, H. C. Meyer, and J. D. Stettler, "Laser Interaction and Related Phenomena," Vol. 2, Ed. by H. J. Schwarz and H. Hora (Plenum, New York, 1972) p. 2 .

11. J. T. Jefferies, "Spectral Line Formation" (Blaisdel1, Waltham, Mass, 1968) p. 119 .

12. H. R. Griem, "Plasma Spectroṣonpy" (MrGraw-Hi11, New York, NY, 1964).

13. H. Pepin, F. Martin, B. Grek, T. W. Johnston, J. C. Kleffer, and G. Mitchel, J. Appl. Phys. 50, 6784 (1979).

14. P. E. Dyer, S. A. Ramsden, J. A. Sayers, and M. A. Skipper, J. Phys. D $\underline{9}$, 373 (1975). 
15. A. I. Merts, R. D. Cowan, and N. H. Magee, Jr., "The Calculation of Power Output from a Thin Iron-Seeded Plasma," Los Alamos Scientific Report LL-6220-MS (1976), unpublished.

16. H. Eyring, J. Walter, and G. E. Kimball, "Quantum Chemistry", (Wiley, New York, 1954) p. 163.

17. T. A. Carlson, C. W. Nestor, Jr., N. Wasserman, and J. D. McDowe11, Atoric Data $2,63(1970)$.

18. V. A. Gaponov, G. A. Pasmanik, and A. A. Shilov, Sov. J. Quantum Electron. (U.S.A), 8,1009 (1978) (translation of Kvantovaya Elektron., Moskva (U.S.S.R) $\underline{5}, 1780(1978)]$.

19. M. D. Rosen, D. W. Phillion, V. C. Rupert, W. C. Mead, W. L. Kruer, J. J. Thomson, H. N. Kornblum, V. W. Slivinsky, G. J. Caporaso, M. J. Boyle, and K. G. Tirsell, Phys. Fluids 22, 2020 (1979).

20. H. Pepin, B. Grek, F. Rheault, and D. J. Nagel, J. Appl. Phys. 48, 3312 (1977).

21. R. D. Bleach and D. J. Nagel, J. Appl. Phys. 49, 3832 (1978).

22. A. L. Hoffman and E. A. Crawford, J. App1. Phys. 49, 3219 (1978).

23. K. M. Glibert, J. P. Anthes, M. A. Guslnow, M. A. Palmer, R. R. Whitlock, and D. J. Nage 1, J. App1. Phys. 51, 1449 (1980).

24. D. J. Nagel, P. G. Burkhalter, G. A. Doschek, C. M. Dozier, U. Feldman, B. M. Klein, and R. R. Whitlock, N.R.L. Report No. 7838, 1974, pp. 65-120 (unpublished).

25. J. P. Anthes, K. M. Glibert, M. A. Palmer, and M. K. Matzen, Proceeding of the 6th IEEE International Conference on Plasma Sclence, Montrea1, Quebec Canada (1979).

26. M. Keith Matzen, private communication. 
Table I.

Typlcal values for $\Delta E_{s}$ are shown to display the Z-dependence of line radiation from the $K, L$, and $M$ shells. See Eqs. (14) and (15) plus the discussion following these equations.

\begin{tabular}{|c|c|c|c|c|c|c|}
\hline$z$ & K-shell & L-shel1 & $\mathrm{z}$ & K-shell & L-shell & M-she11 \\
\hline 0 & 0.352 & & $4 \dot{0}$ & Ih.\% & 2.56 & \\
\hline 9 & 0.804 & & 45 & 20.6 & 3.29 & 0.463 \\
\hline 13 & 1.69 & & 50 & 25.4 & 4.12 & 0.630 \\
\hline 15 & 2.26 & & 60 & 36.6 & 6.06 & 1.03 \\
\hline 20 & 4.03 & 0.562 & 70 & 49.8 & 8.39 & 1.52 \\
\hline 25 & 6.32 & 0.920 & 80 & 65.1 & 11.1 & 2.14 \\
\hline 30 & 9.11 & 1.36 & 90 & 82.4 & 14.2 & 2.87 \\
\hline 35 & 12.4 & 1.92 & & & & \\
\hline
\end{tabular}




\section{Table II}

Values for the parameters appearing in Eqs. (1) - (12) are IIsted for the various applications discussed in the text. Cases 1-4 are discussed in the Uniform Preformed Plasmas Section and Case 5 is discussed in the Hot-Spot Model Section.
Case 1
Case 2
Case 3
Case 4
Case 5

\begin{tabular}{|c|c|c|c|c|c|}
\hline$p_{0}$ & 1 & 1 & 2 & 3 & 1 \\
\hline$i$ & 13 & $z$ & $z$ & $z$ & $6,9,13$ \\
\hline$q$ & 0 & 0 & 2 & 10 & 0 \\
\hline$\varepsilon_{\mathrm{d}}$ & 1.0 & 1.0 & 1.0 & 1.0 & $1.0(0.4)$ \\
\hline$n_{e}$ & $10^{21} \mathrm{~cm}^{-3}$ & $10^{21} \mathrm{~cm}^{-3}$ & $10^{21} \mathrm{~cm}^{-3}$ & $10^{21} \mathrm{~cm}^{-3}$ & $10^{21} \mathrm{~cm}^{-3}$ \\
\hline$r$ & $0.03 / 0.05 \mathrm{~cm}$ & -- & -- & -- & $0.0023 \mathrm{~cm} *$ \\
\hline$d$ & $2.5 \mathrm{~cm}^{+}$ & $2.5 \mathrm{~cm}^{+}$ & $2.5 \mathrm{~cm}^{\dagger}$ & $2.5 \mathrm{~cm}^{+}$ & $--*$ \\
\hline$\Delta \mathrm{t}_{i}$ & $10^{-9} \mathrm{sec}$ & $10^{-9} \mathrm{sec}$ & $10^{-9} \mathrm{sec}$ & $10^{-9} \mathrm{sec}$ & $2.5 \times 10^{-11} \mathrm{sec}$ \\
\hline$\Delta t_{p}$ & $10^{-9} \mathrm{sec}$ & $10^{-9} \mathrm{sec}$ & $10^{-9} \mathrm{sec}$ & $10^{-9} \mathrm{sec}$ & $10^{-9} \mathrm{sec}$ \\
\hline $\mathbf{f}$ & 2.0 & 2 & 8 & 18 & 2 \\
\hline$\varepsilon_{r}(b b)$ & 0.124 & 0.124 & 0.124 & 0.124 & 0.013 \\
\hline
\end{tabular}

$+A=\pi r^{2}$ and $V=\pi r^{2} d$, where $d$ is the plasma depth.

$\star V=(4 / 3) \pi r^{3}$ 
Table III

The parameter $C_{2}$, defined by $E_{q} .(21)$ and determined by data fron the indicated reference, is tabulated. The type of laser used to create the plasma is also indicated. The Ref. 5 value was deduced from the exploding-wire preformed plasma example and the Ref. 8 value pertalns to the hot-spot model. The varlous quantities used to tit the expertmental datif from Refs. 20, 23, and 24 are alsi) listed. The listed z-values are near but not necessarily at the observed maxima. Thi: peak due to M-sheil radiation given by Ref. 20 was not treated because the observed maximum occurred for $Z \sim 47$ and the theoretical maximum is predlcted For $z \sim 60$. The experimentally determined temperatures are given in the last coliumn.

\begin{tabular}{|c|c|c|c|c|c|c|c|}
\hline Laser(Ruf.) & K shell. & L shell & M shell & K shell & L shell & M shell & $\mathrm{kT}_{\mathrm{e}} / \mathrm{keV}$ \\
\hline $\mathrm{CO}_{2} \quad(20)$ & $5 \cdot 3-3$ & $1.7-3$ & -- & $12 /(1.44)$ & $26 /(1.00)$ & -- & 0.30 \\
\hline Ruby $(21)$ & $1 \cdot 3-3$ & $4 \cdot 4-3$ & $1.8-3$ & $8 /(0.633)$ & $25 / 0.920)$ & $55 /(0.023)$ & 0.07 \\
\hline Nd-Glass (23) & 3.0 & 14.7 & 11.5 & $12 /(1.44)$ & $26 /(1.00)$ & $52 /(0.704)$ & 0.365 \\
\hline Nd-GLass $(24)$ & 4.8 & 17 & 30 & $12 /(1.44)$ & $29 /(1.26)$ & $64 /(1.22)$ & 0.70 \\
\hline Nd-Glass (5) & 16.3 & & & & & & \\
\hline Nd-Glass ( 8 ) & 1.71 & & & & & & \\
\hline
\end{tabular}


Figure Captions

Elgure 1. Predtctions based on the parameters given by the Case 1 column in Table II are shown. The straight line corresponds to optimal eff 1clency, $r_{i}=\eta(b b)=0.23$. Curves 1 and 2 refer respectively to the $r=0.05 \mathrm{~cm}$ and $r=0.03 \mathrm{~cm}$ cases. The $O$ data points are taken from Fig. 13 of Ref. 5 and these data should be compared to Curve $l$. The $\square$ points were taken from the text of Ref. 5 and they should be compared to Curve 2 .

Figure 2. The efflciency for $k$-shell radiation, $\eta=\eta(b b)$, is shown for a uniform plasma consisting of a single material with atomic number. 7. The nominal energy of the radiation is $\Delta \mathrm{F}_{\mathrm{s}}$. This prediction corresponds to the maximum effictency achievable for the chotce of parameters 11 sted as Case 2 in Table II.

Elgure 3. The efflciency for L-shell radiation, $\eta=\eta(b b)$, is shown for a uniform plasma consisting of a single material with atonic number 2. The nominal energy of the radiation is $\Delta \mathrm{E}_{\mathrm{s}}$. This prediction corresponds to the maximum efficiency achievable for the cholce of parameters Iisted as Case 3 in Table IL.

Figure 4. The effictency for $M$-shell radlation, $\eta=\eta(b b)$, is shown for a uniform plasma consisting of a single material with atomic number 7. The noninal energy of the radiation is $\Delta E_{s}$. ThIs prediction. corresponds to the maximum efficlency achlevable for the cholce of parameters 11 sted as Case 4 in Table II. 
Figure 5. Data from the hot-spot model of Ref. 8 for the K-shell radiation efflciency from carbon, fluorine, and aluminum plasmas are sliown as solid curves. The broken curves are the results from the present model with the paraters listed as Case 5 in Table II and $\eta=\eta(b b)$. The - - is the salle as broken curves but with $\varepsilon_{d}$ replaced by the parenthetieal ontry given indei Case 5 in Table II.

Figure 6. The relative intensity, labled ergs/sr, of radiation produced by ruby laser Irradiation of eargats will lluclear chäré \% is plotecd as $O$ for detector response to $0.6 \mathrm{keV}$ or greater radiation, au $\Delta$ for $0.9 \mathrm{keV}$ radiation, and as 0 for $1.0 \mathrm{keV}$ radiation. These expertmental data are taken from Ref. 21 and the data points are connected by stralght. lines for visual purposes. The docted and broken lines are theoretical curves discussed in the text.

Figure 7 . The effective $\mathrm{kT}_{e}$ is shown as a function of $\mathrm{J}_{\mathbf{i}}$. These data are based on theoretical results from Ref. 26 for $1.06 \mu$ in radiation impinging on a solid Ni target. The solid line is a fit by Eq. (20) descrihed In the text.

Figure 8. The efficiency for producting radiation in a certain frequency range is shown as a function of $J_{i}$. The $\odot$ data points are for

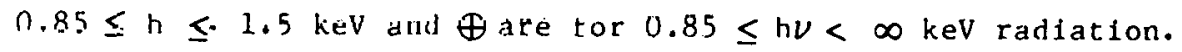
These data are based on theoretical results from Ref. 26 for $1.06 \mu \mathrm{m}$ radiation incldent upon a solid Ni target. The suldd curve is based on the present theory as discussed in Sec. III. 


$$
\text { If }
$$




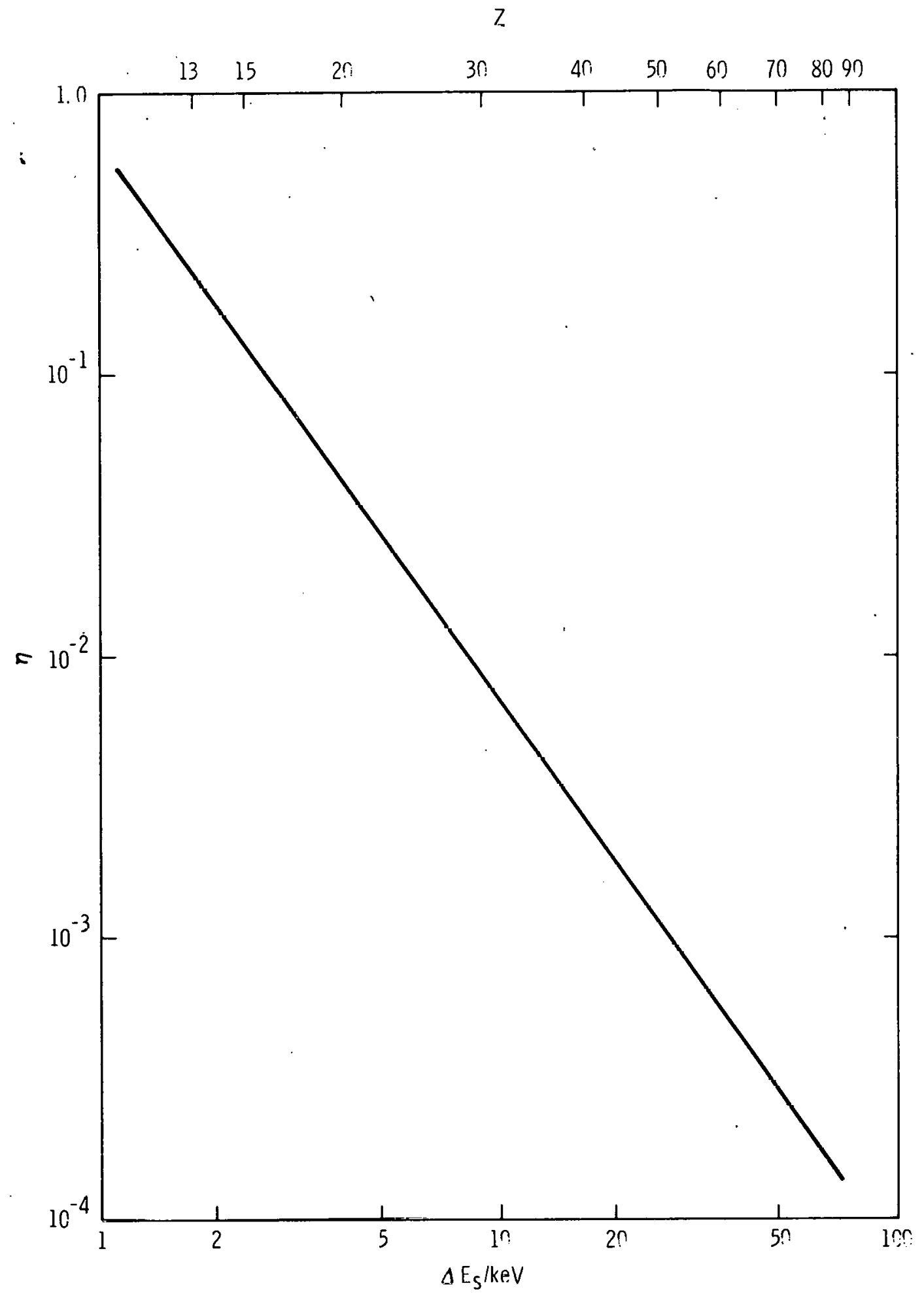




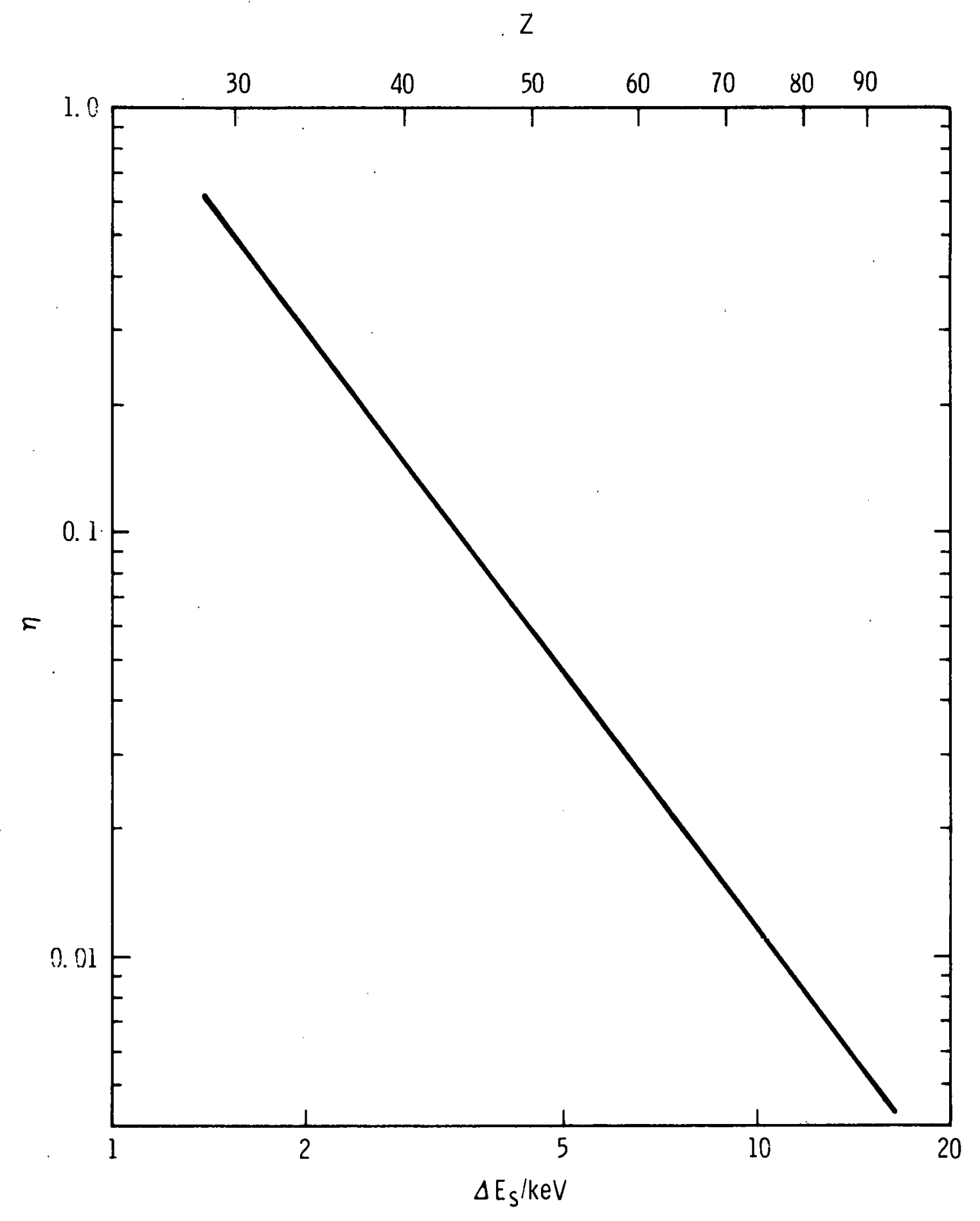




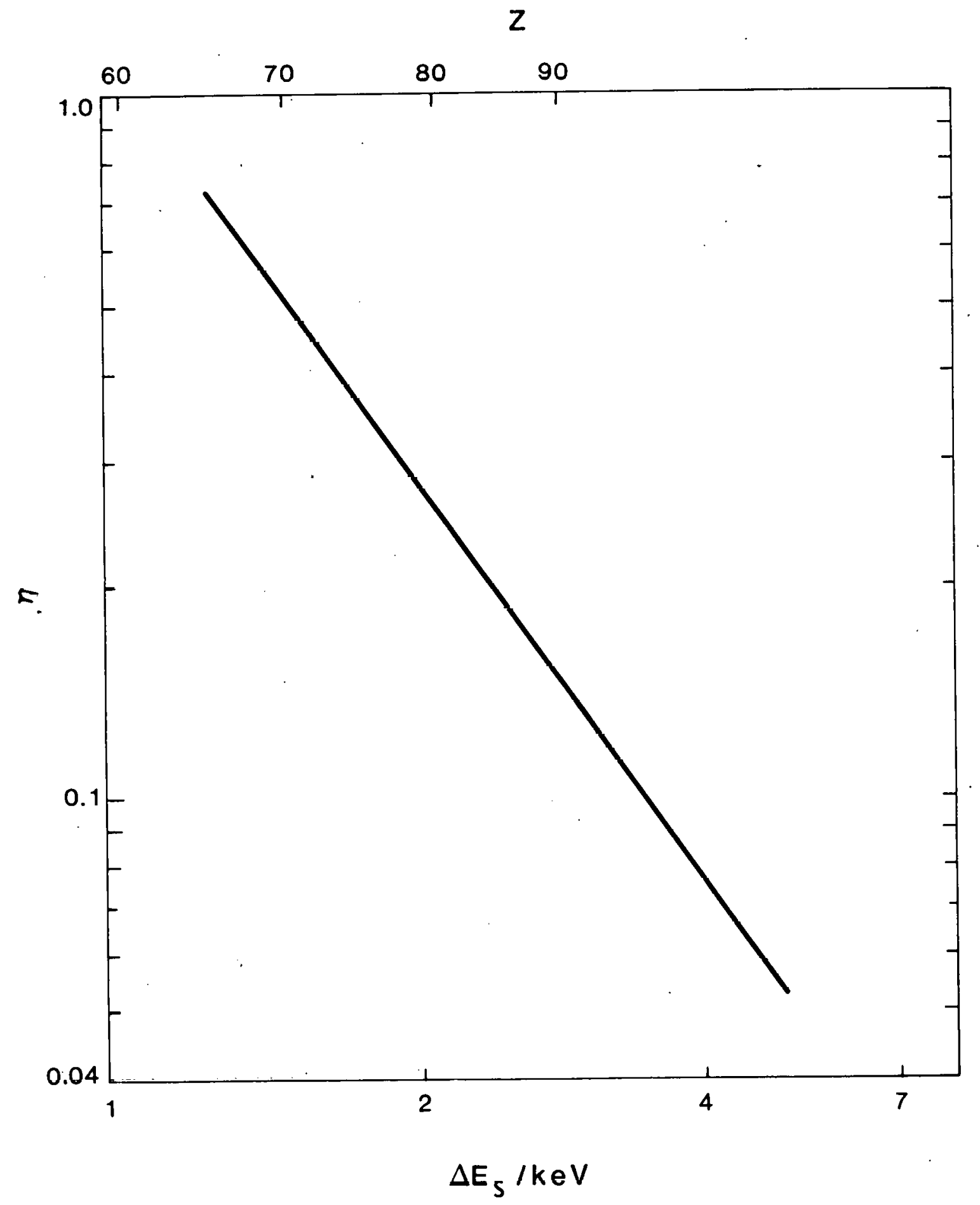




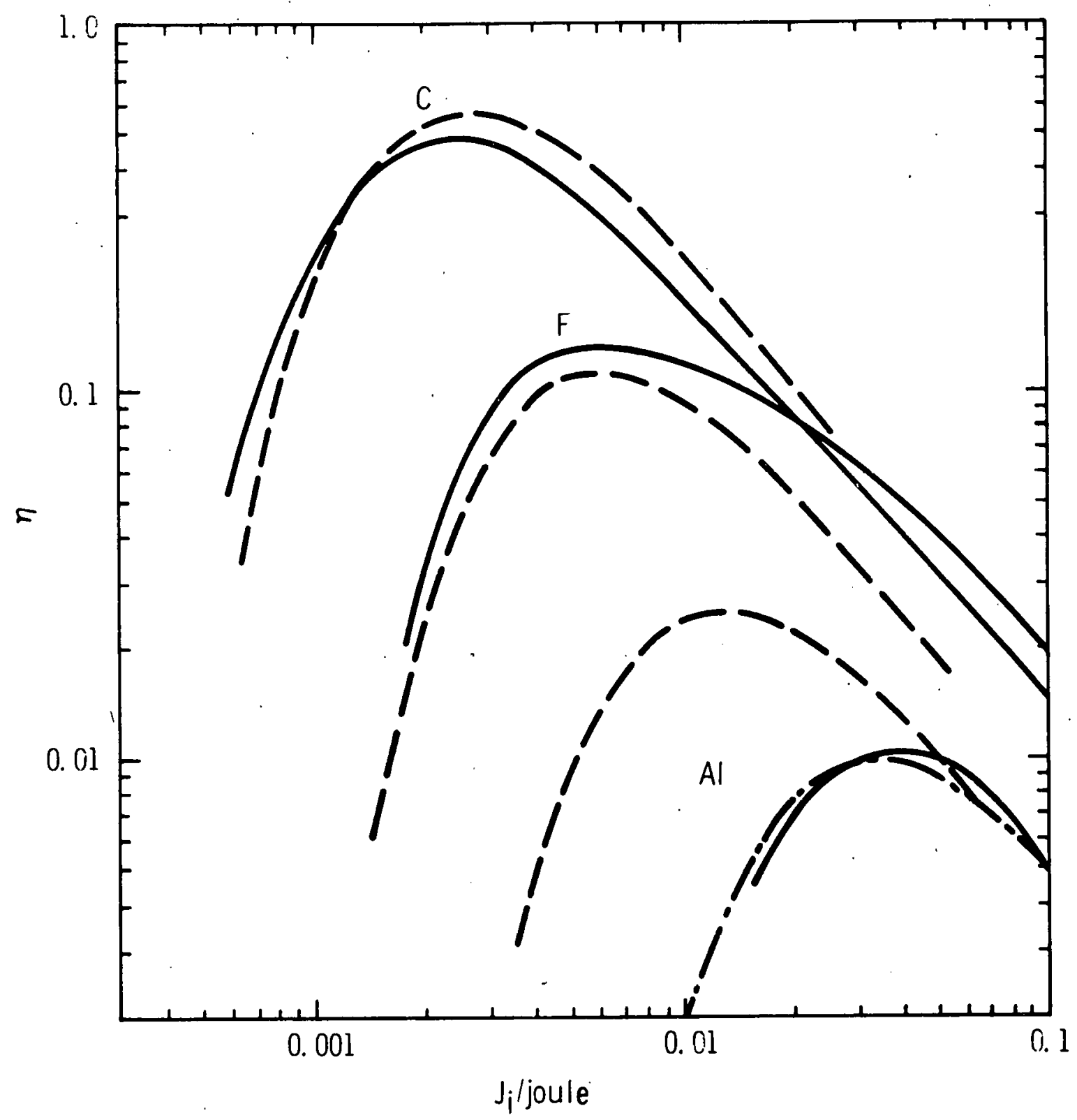




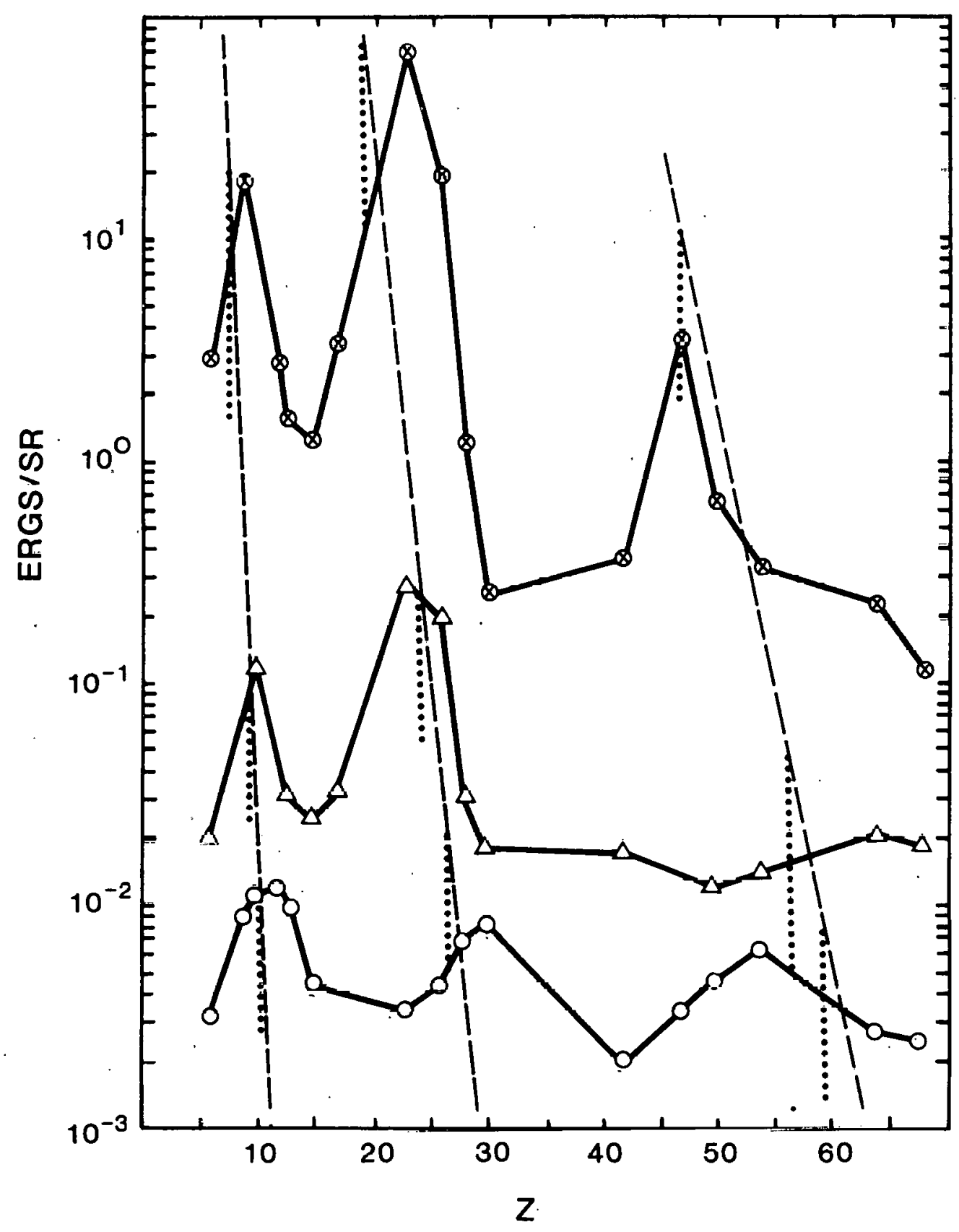




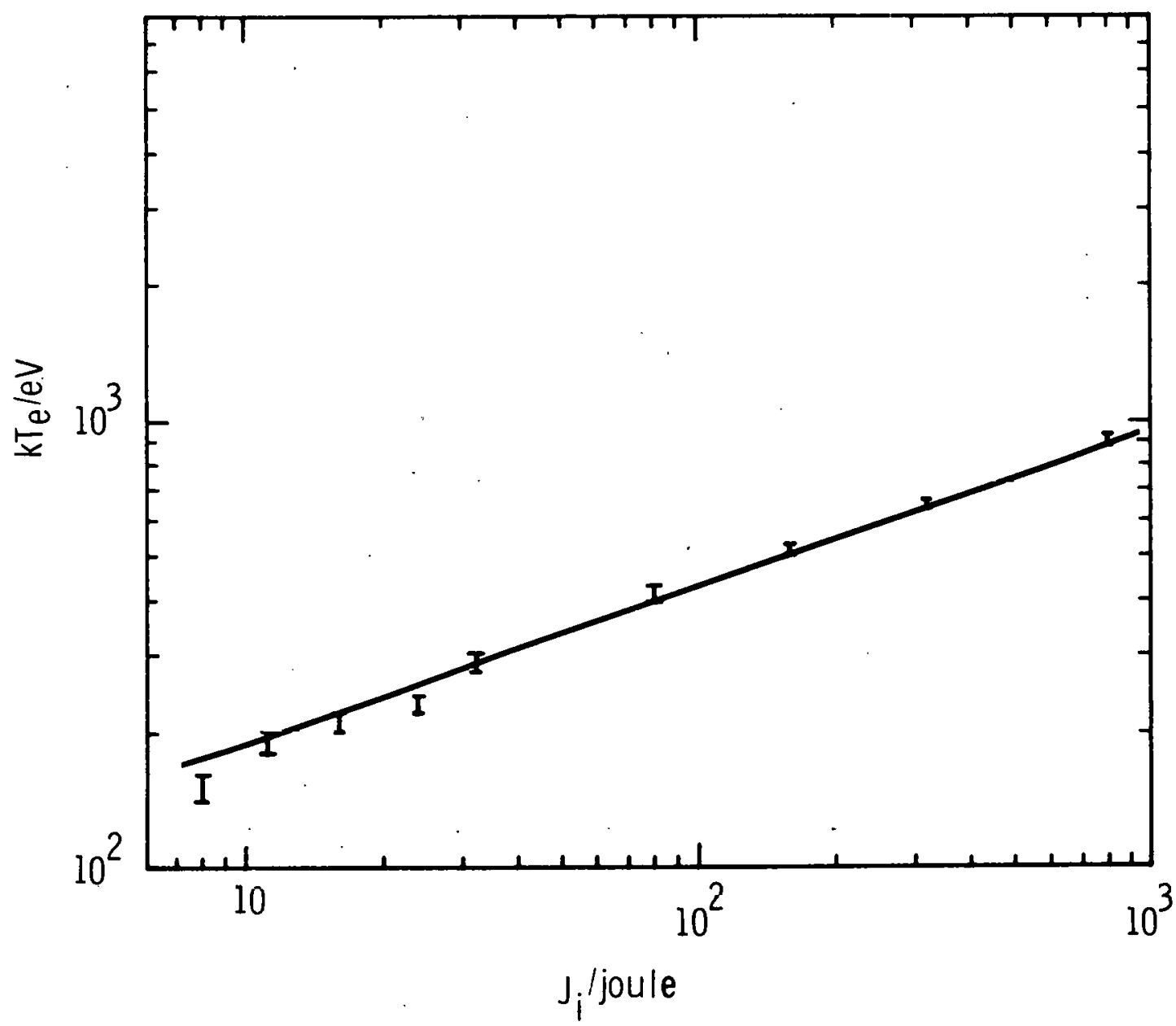




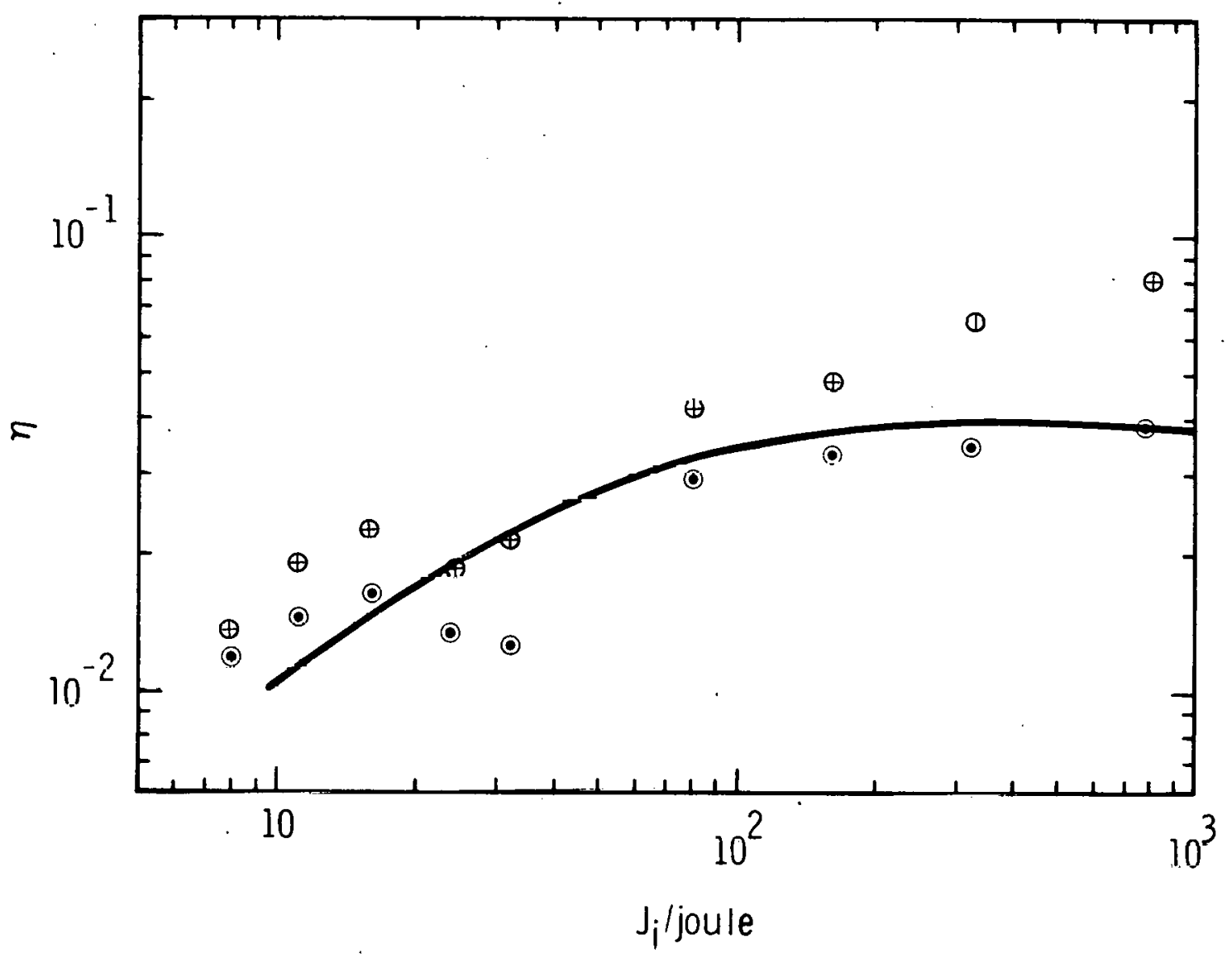


Distribution:

Los Alamos Sclentific Laboratory (3)

P.O. Box 1663

Los Alamns, NM 87545

Attn: D. C. Cartwright, Theory Div.

A. L. Merts, Group T4

W. F. Huebner, Group T4

Professor J. J. Duderstadt

Department of Nuclear Englneerling

University of Michigan

Ann Arbor, MI 48105

Naval Research Laboratory (4)

Washington, DC 20375

AttN;: Jack Davis, Code 6709

K. J. Whitney, Code 6709

D. J. Nagel

D. Mosher

4000

4200

4210

4211

4211.

42.11

4211

4212

4214

42.16

4218

4220

4230

4231

4231

4231

4234

4240

4241

4242

4243

4247

4247

4247

4250

4252

8266

3141

3151

A. Narath

G. Yonas

J. B. Gerardo (3)

E. J. McGulre

T. A. Green

J. M. Peek (20)

M. E. Riley

R. A. Gerber

E. D. Jones

A. W. Johnson

J. K. Rice

M. Cowan

J. E. Powe 11

J. H. Renken

C. MacCallum

J. E. Morel

T. P. Anthes

G. W. Kuswa

T. P. Wright

P. MIX

J. Chang

$M$. Widner

T. W. Hussey

M. K. Matzen

T. H. Martin

D. H. McDaniel

E. A. Aas

T. L. Werner (5)

W. L. Garner (5)

(for DOE/TIC)

3154-3 R. P. Campbel1 (25).
Dr. M. D. Rosen

Lawrence Livermore National Laboratory L-477

P. 0. Box 808

Livermore, CA 94550

Dr. R. W. P. McWhirter

Culham Laboratory

Abingdon, Oxforshire

ÉNGLAND 


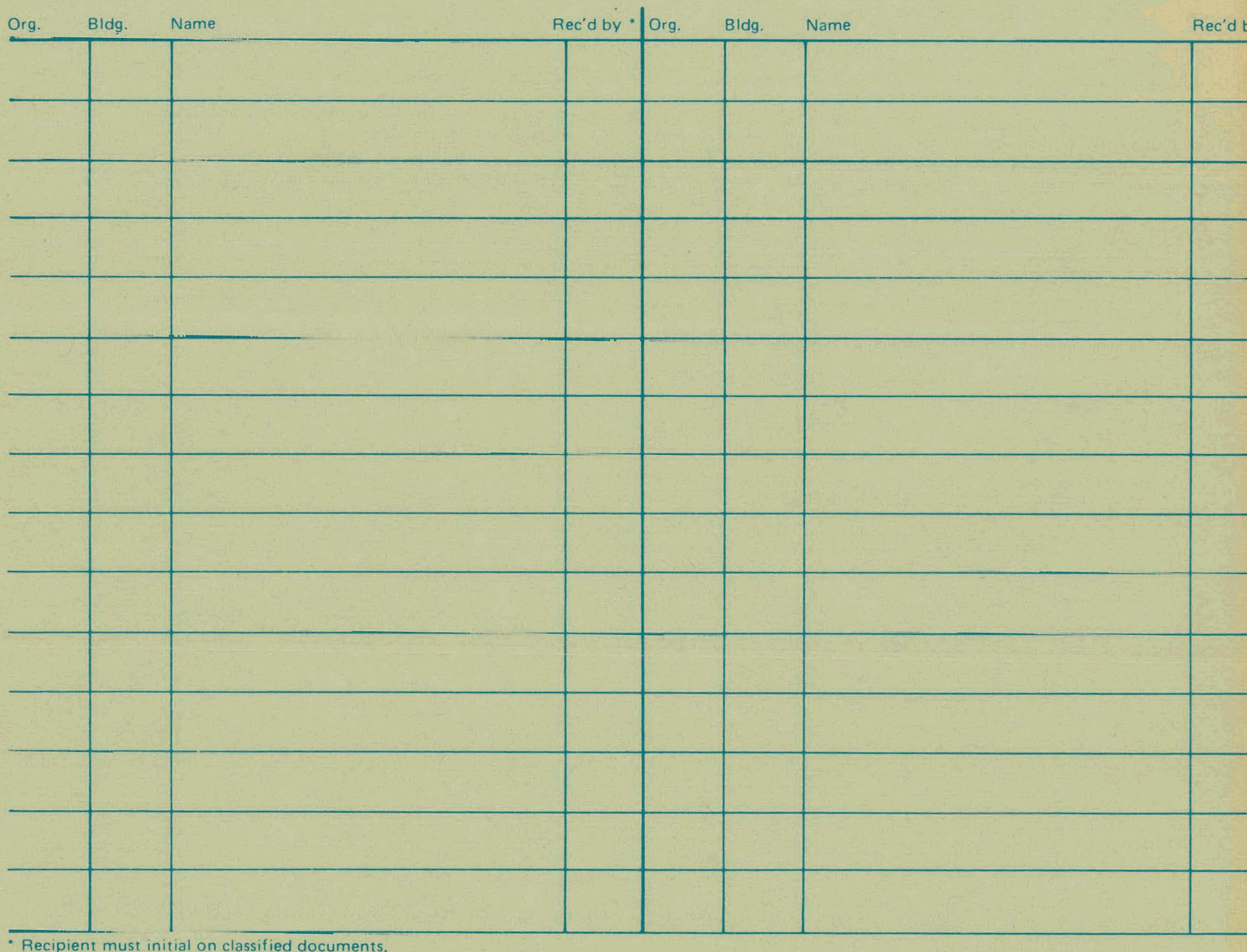

- Recipient must initial on classified documents. 